\title{
Searching for Enduring Donor Relationships: Evidence for Factors and Strategies in a Donor/ Organization Integration Model for Fund Raising
}

Received (in revised form): May 31, 2005

\section{Tanise L. Chung-Hoon}

Dr. Tanise L. Chung-Hoon is Co-Director of Principal Gifts for LDS Philanthropies, Brigham Young University, and is a Certified Fund Raising Executive (CFRE). Her research focuses on enduring donor relations, donor inclination, and the role of organizational integration in creating long-term support for nonprofit institutions.

\section{Julie M. Hite}

Dr. Julie M. Hite is an Assistant Professor at Brigham Young University in the Department of Educational Leadership and Foundations. Her research focuses on the strategic networks of educational organizations, particularly as they affect resources, innovation, and educational performance.

\section{Steven J. Hite}

Dr. Steven J. Hite is Professor of Educational Research Theory and Methodology at Brigham Young University. His current research and service endeavors include the application of geographical information systems with educational management information systems in the national and regional education sectors of Africa and South Asia.

\begin{abstract}
Higher education relies upon private philanthropy as a significant source of outside revenue, yet competition for donor resources escalates annually. Competency for building enduring donor relationships may positively influence institutional fund-raising outcomes by addressing this problem. Qualitative data
\end{abstract}

\section{Author's Contact Address:}

Tanise L. Chung-Hoon, PhD, CFRE

Brigham Young University

1173 CONF

Provo, UT 84602, USA

Phone: + 18014229033

Email: tanise@byu.edu are presented examining the utility of the Donor/Organization Integration Model for identifying long-term donor linkage. In the context of three public institutions of higher education, relational embeddedness interaction and formal structural interaction were specifically identified as factors. Four distinct strategies were found to illustrate interaction between individual relationships and organizational structure to categorize donor integration levels.

\section{Keywords:}

bigher education, fund-raising strategy, donor relations, networking, organizational planning 


\section{Introduction}

With the trend of declining financial support from state and federal government, higher education institutions are finding that they must develop supplemental revenue streams to maintain institutional survival and growth. ${ }^{1}$ Higher education as an industry has clearly accepted the need to access resources beyond formal organizational boundaries.

In higher education, a significant source of outside revenue has been private philanthropic giving. ${ }^{2}$ Private

philanthropy is accessed through individual donors who influence, own, or control scarce assets that can specifically promote the institution's mission and vision. This fund-raising process is often a competitive venture that depends on purposefully cultivating crucial funding ties with individual donors. Thus successful fund-raising outcomes in higher education may be contingent on developing enduring personal exchange relationships with donors.

Enduring donor relationships are quickly becoming a necessity for higher education institutions in their attempts to develop a unique fund-raising competency that creates a competitive advantage. ${ }^{3}$ To enhance fund-raising capacity and successfully compete for donor funds, higher education institutions must examine their current relational and structural strategies for developing these critical philanthropic partnerships with private donors. 4

This article addresses the critical need for higher education organizations to develop effective and enduring strategic fund-raising relationships with current donors and prospective donor publics. Understanding the combination of relational and structural strategies that can support successful and enduring donor relations may provide a critical link and learning opportunity for higher education leaders as they design their fund-raising operations, activities, and policies in order to access resources from their external environments. Building upon the theoretical framework in the Donor/ Organization Integration Model for identifying and creating enduring donor relationships, ${ }^{5}$ this study uses qualitative methods to address two research questions:

1. How do institutions strategically identify, cultivate, and develop integrated donor relationships?

2. What organizational involvement strategies and structural process factors may lead to a donor's enduring financial support for the institution?

\section{Background}

Higher education institutions regularly compete to attract and retain the most state and federal funding and the most beneficial relationships with private donors to maintain organizational viability and growth. ${ }^{6}$ Drawing from strategic theory which seeks to explain why certain organizations outperform others, we have found that the concept of positive differential performance, termed competitive advantage, suggests that highperforming organizations have abilities that provide an operational edge over a competitor for a sustained period of time. ${ }^{7}$ For fund raising in higher education, an organization must have a distinctive fund-raising capacity to have a sustained ability to build enduring donor relationships. $^{8}$

Educational fund raising in the United States is a competitive enterprise. 9 In 2002, a record year for giving, overall charitable donations in the US totaled an estimated $\$ 239 \mathrm{bn}$, of which nearly 13 percent $(\$ 32 \mathrm{bn})$ was designated for 
education, all levels included. ${ }^{10}$ Private individuals traditionally provide 75 percent of charitable educational funding, and educational organizations on all levels are competing for those resources. ${ }^{11}$ In this competitive market, individual donors who hold or control resources are in positions of power. Prospective donors receive a stream of never-ending appeals for funding from many worthy nonprofit entities, which often makes the decision of which cause to support and which organization to partner with a complex challenge. ${ }^{12}$

With the heightened level of competition, donors are expecting more from their philanthropic experiences. ${ }^{13}$ Higher education institutions that are able to provide significant and meaningful donor experiences, more fully integrating the donor with the organization, may set themselves apart from the rest. ${ }^{14}$ However, integrating donors requires that institutions have a clear organizational vision, as well as strategic efforts focused on aligning institutional infrastructure to develop enduring donor relations. Organizations that develop enduring donor relations through an integrated fund-raising capacity will likely increase their chance of rising above their competition.

An enduring donor relationship is characterized by a significant relational quality and depth between donor and organization, as well as a significant level of formal structural interaction with the organizational infrastructure. ${ }^{15}$ Enduring donor relationships are evidenced by high levels of personal relationships, economic interactions, social capital, and personal commitment; by significant personal integration into the formal structure and activities of the institution; and by high levels of trust. Donors with enduring relationships are fully engaged with the organization and are willing to give their time, talent, and treasure to see the organization succeed. To consistently create such enduring donor relationships higher education institutions must make strategic organizational efforts that go beyond transactional give-and-take exchanges between donor and organization.

The Donor/Organization Integration Model offers a framework to strategically identify, cultivate, and develop enduring donor interactions. ${ }^{16}$ This model suggests that higher education organizations should seek opportunities to integrate potential external donors both relationally and structurally within the organization (see Figure 1). As the model shows, the interactions between the donor and the organization are assessed along two dimensions: relational embeddedness interaction and the formal structural interaction. The four quadrants of this model illustrate the types of integration that may be created by relational embeddedness and the formal structural interaction with the organization.

In the model, relational embeddedness interaction is defined simply as the strength of an individual donor's (or potential donor's) relational connection to people within the organization. Thus a minor or weak interaction represents more superficial, or transactional, relationships, while a major or strong interaction represents genuine relationships with a significant degree of personal connection, experience, involvement, social capital, personal investment, and trust between the actors that may have evolved over time from weak to strong. ${ }^{17}$ This relational tie can be from the donor to either one or many persons within the organization (acting as organizational agents) as well as to the organization itself. 


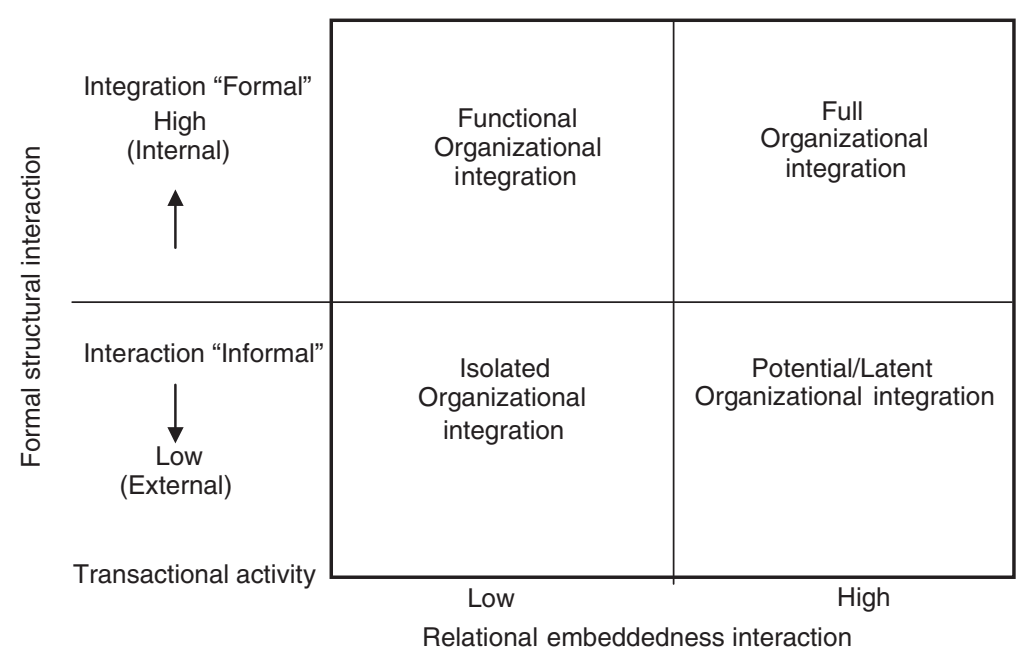

Figure 1: Donor/Organization Integration Model (DOIM)

In the model, formal structural interaction is defined as the degree to which the actor is structurally embedded within, or formally linked to, the organizational infrastructure. Formal structural interaction moves along a spectrum of activity that includes the recognized organizational boundary and the degree to which external constituents are integrated within the organizational infrastructure. ${ }^{18}$ Low formality exists when the donor interacts with the organization in a purely transactional, or "give and take," market exchange that occurs on a very limited basis outside the organization's boundaries. Transitional formality, a middle or transition point termed interactive involvement, exists when structural interaction is increased between the actor and the organization, although this interaction is generally on the external edge of the organization's formal boundaries. One type of transitional formality is a donor pledge: the pledge initiates the internal monitoring process through the gift management structure, but the interaction with the prospective donor is still external to the organization until an actual donation is made. High formal structural interaction exists when the donor is structurally maintained and supported and has become formally linked within the organizational boundaries (eg, formal position of involvement).

These two dimensions of donor interaction-relational embeddedness and formal structural interaction-provide a framework for understanding donor relations. The model suggests that enduring donor relations are more likely to occur as both dimensions increase. Building on this theoretical framework of the Donor/Organization Integration Model, ${ }^{19}$ this study seeks to further understand how higher education institutions identify and create enduring donor relationships, specifically in terms of relational embeddedness and formality of structural interaction. In addition, the study seeks to ascertain what organizational integration strategies may lead to a donor's enduring financial support for the institution. 


\section{Method}

The researchers conducted semistructured interviews to collect data from fundraising employees and administrators at three higher educational institutions in a western state of the United States (see Appendix A). These institutions were purposefully sampled as organizations that face an equivalent political and economic environment. The main selection criterion was Carnegie Foundation classification, with one institution being chosen randomly from each of the following: baccalaureate/associates colleges, masters colleges and universities II, and doctoral/ research universities-intensive. ${ }^{20}$ The Carnegie classifications provide a clear typology to define organizational activities and processes as well as a way to compare organizations between categories. In addition, the inclusion criterion of organizational size ensured the participation of fund-raising operations at small, medium, and large schools. The three schools were given pseudonyms representing their characteristics: Flagship University, Northgrowth State University, and Central College.

In-depth personal interviews, from one hour to three hours in length, were conducted with three informants at each of the three institutions $(n=9)$. The first informant selection criterion was an obvious involvement with fund-raising activities as identified by title in the Council for Advancement and Support of Education (CASE) 2003-04 Membership Directory. The three informants at each institution represented various levels of organizational authority and influence on policy, structure, and internal coordination, ranging in position from president to annual fund coordinator. The second informant selection criterion was that each informant represented a different functional role, one of the three levels of a development organization's activity corresponding with Worth and Asp's vector paradigm model that categorizes fund-raising responsibilities based on internal or external focus. ${ }^{21}$ The semistructured interviews focused on the informants' perspectives of the influence of donor relationships and internal organizational structure on the school's ability to access external resources, specifically by fund-raising activities. Qualitative coding and analysis of the nine transcribed informant interviews was performed using QSR NVivo software to evaluate the data collected. ${ }^{22}$

Follow-up reviews and discussions with both fund-raising experts in higher education and the initial informants (member checks) were conducted to further clarify and understand the factors that emerged from the data and to increase the trustworthiness of the findings. ${ }^{23}$ The themes, propositions, and models that emerged from the qualitative analysis were continually compared with previous research and literature related to fund raising, higher education, boundary spanning, organizational theory, strategic theory, and network theory.

\section{Factors of Enduring Donor Relationships}

The first research question addresses how higher education institutions identify, cultivate, and develop enduring donor relationships. Using the framework of the Donor/Organization Integration Model, ${ }^{24}$ the researchers evaluated whether the case data supported the theoretical constructs of relational embeddedness and formal structural interaction. The key finding of this research is that both of these constructs were well represented in the cases. The interview data provided both primary and secondary factors for each construct that further enhanced their 
descriptions. The inclusion criterion for a primary factor was that the factor be identified in all three cases (100 percent), by at least two respondents per case. The inclusion criterion for secondary factors was identification in at least two of the three cases (66 percent) by at least two respondents per case.

\section{Relational embeddedness}

The construct of relational embeddedness interaction was supported by four primary factors (see Table 1; see Appendix B for constructs and factor definitions). These factors suggest that relational embeddedness interaction is multifaceted, ${ }^{25}$ providing many avenues for developing these relationships.

These factors suggest several points critical to understanding relational embeddedness interaction as it affects fund raising in higher education. First, the two factors of interpersonal activity and social and economic relationships were both found to occur in both dyadic (between two actors) and organizational interactions. This duality is critical because, although relationally embedded interactions generally occur between donors (or prospective donors) and people from within the organization, these relationships do not have to be associated with the organization for a relationally embedded dyadic interaction to exist that can benefit the organization. Secondly, two primary factors suggested that at times asymmetric exchange may result in an individual benefit, but such exchanges may also be combined to create an overall exchange symmetry. For example, donor relations was solely driven by the organization, while donor feedback existed exclusively on the donor side. This mutual benefit makes sense for fund raising because the directionality and degree of personal interaction and communication often modify an economic exchange between donor and institution as well as affecting the perceived quality of the relationship. ${ }^{26}$

Table 1: Primary and secondary factors associated with relational embeddedness of interactions

Relational embeddedness interaction

Dyadic* Organization ${ }^{* *}$ \# of Passages \# Respondents

Primary factors

All cases (two or more respondents/case)

Interpersonal activity

Social and economic relationships

Donor relations

Donor feedback

Secondary factors

At least two cases (two or more respondents/case)

Appreciation

Control

Frequency of contact

Donor passion

$\begin{array}{rrrr}\mathrm{x} & \mathrm{x} & 69 & 9 \\ \mathrm{x} & \mathrm{x} & 53 & 9 \\ & \mathrm{x} & 25 & 7 \\ \mathrm{x} & & 9 & 6\end{array}$

*Dyadic indicates factors that occur between actors that may not be organizationally related. **Organization denotes factors of activity and effort that occur within the organizational boundary. 
Table 2: Primary and secondary factors associated with formality of structural interaction

\begin{tabular}{|c|c|c|c|c|}
\hline & \multicolumn{4}{|c|}{ Formal structural interaction } \\
\hline & Dyadic* & Organization $* *$ & \# of Passages & \# Respondents \\
\hline \multicolumn{5}{|l|}{$\begin{array}{l}\text { Primary factors } \\
\text { All cases (two or more respondents/case) }\end{array}$} \\
\hline Internal organization operations & & $\mathrm{x}$ & 178 & 9 \\
\hline Fund-raising process & $\mathrm{x}$ & $\mathrm{x}$ & 70 & 9 \\
\hline Roles for external actors & $\mathrm{x}$ & $\mathrm{x}$ & 41 & 9 \\
\hline Organizational challenges for fund raising & & $\mathrm{x}$ & 21 & 9 \\
\hline Evaluation and assessment & & $\mathrm{x}$ & 19 & 8 \\
\hline \multicolumn{5}{|l|}{$\begin{array}{l}\text { Secondary factors } \\
\text { At least two cases (two or more respondents/case) }\end{array}$} \\
\hline Organizational external operations & $\mathrm{x}$ & $\mathrm{x}$ & 24 & 5 \\
\hline Teaching about fund raising & $\mathrm{x}$ & $\mathrm{x}$ & 11 & 5 \\
\hline Institutional context: location/community & & $\mathrm{x}$ & 10 & 5 \\
\hline
\end{tabular}

*Dyadic indicates factors that occur between actors that may not be organizationally related. **Organization denotes factors of activity and effort that occur within the organizational boundary.

The implication for fund raising practice is that if relational embeddedness interaction factors are ignored by the organization, the potential for strategically managing enduring donor interactions is severely impaired: that is, the opportunity for increased fund-raising outcomes as a result of positive personal and economic relationships becomes a hit-and-miss possibility. Additionally, the data support the literature that defines relational embeddedness as a combination of social and economic activity, ${ }^{27}$ which suggests that successful fund-raising practice requires a symmetry of communication and interaction between donor and recipient. $^{28}$

\section{Formal structural interaction}

This construct identifies the degree to which an individual is connected formally to the organization within its recognized boundaries. ${ }^{29}$ The primary and secondary factors of formality of structural interaction are found in Table 2. (See
Appendix C for construct and factor definitions.) In the data, formal structural interaction was a very rich construct that illustrated the organizational complexity of fund-raising activity. A key finding is that each of the primary factors emerged relative to the organization's formal boundary, suggesting that the extent of organizational control, which is greater within the formal organizational boundaries, is an integral element of formal structural interaction with donors. For example, the factors of internal organization, challenges for fund raising, and evaluation and assessment are each within the internal boundary of the organization. Donor interactions along these factors may be more formalized and asymmetrical because the organization defines and controls the processes and outcomes. On the other hand, the factors of roles for external actors and fund-raising process occur in a more dyadic environment, requiring greater bridging between the internal organization and the external 
environment and likely a greater symmetrical exchange of control. This bridging suggests a lower degree of formal structural interaction given that more elements are outside the control of the organization.

Another key finding is that formal structural interaction may also be influenced by the extent to which the organization and the donor mutually recognize their interaction as official. As indicated in roles for external actors, for example, a person who is on a volunteer fund-raising board may participate in name only because the individual has no inclination or desire to actually serve. While the donor is formally recognized from the organizational perspective, the value of having him or her assume a role within the organization may be dubious until the individual personally chooses to engage and contribute.

Thus the data reflected the literature on boundary spanning, communication, and fund raising, ${ }^{30}$ suggesting that the greater the symmetry of interaction, the greater the benefit for fund raising. When control, decision making, information, motivation, and recognition are asymmetrical, particularly when flowing only from the direction of the organization, the ultimate longevity of donor interaction and commitment may be difficult to sustain.

\section{Integration}

A third construct emerged from the data when the desired symmetry between relational embeddedness interactions and formality of structural interactions occurred between the donor and the organization. This third construct was a purposeful integration that resulted when high levels of both foundational constructs were in place.

The primary factors of integration were found to be purposeful organizational activities or strategies that require conscious thought, deliberate planning, and effort by the institution as a whole (see Table 3 and Appendix D).

The factors of coordination and structural

Table 3: Primary and secondary factors associated with integration

Integration

Dyadic* Organization $^{* * *}$ \# of Passages \# of Respondents

Primary factors

All cases (two or more respondents/case)

Coordination

Structural embeddedness

Strategy

Boundary spanning

$\begin{array}{llll}\mathrm{x} & \mathrm{x} & 33 & 9 \\ \mathrm{x} & \mathrm{x} & 33 & 8 \\ & \mathrm{x} & 26 & 8 \\ & \mathrm{X} & 26 & 7\end{array}$

Secondary factors

At least two cases (two or more respondents/case)

Donor inclination

Types of gifts

Influence

*Dyadic indicates factors that occur between actors that may not be organizationally related. * Organization denotes factors of activity and effort that occur within the organizational boundary. 
embeddedness focused primarily on dyadic integration. However, the factors of positioning and visioning and boundary spanning focused on integrating the organization with its external environment. In contrast, the secondary factors appear to be almost exclusively donor-focused, requiring a higher-level integration by the organization and the donor in tandem. The secondary factors strongly reflect the fundraising literature that discusses the "supply side" or donor driven aspect of philanthropy, ${ }^{31}$ which appears to be a critical component to integration efforts.

The data thus suggest how and why relational embeddedness and formal structural interaction, as well as specific integration strategies, contribute to the cultivation and development of enduring donor relationships. The Donor/ Organization Integration Model proposes that these two dimensions create four different types of donor/organization relationship strategies that may differentially enable an organization to develop enduring donor relationships and, thereby, access external funding. ${ }^{32}$

\section{Integration Strategies for Fund Raising}

The donor/organization relationships described in the data from higher education organizations reflected the four types of organizational integration strategies for fund raising proposed by the Donor/Organization Integration Model.

This section illustrates each of these four types of integration strategies and describes their perceived effectiveness for building enduring donor relations, from the perspectives of the informants who serve in higher education fund raising.

\section{Isolated integration strategy}

The first type of organizational integration strategy is isolated integration, which operates without either high levels of relational embeddedness interaction or formal structural interaction with the organization. A respondent from Flagship University described one facet of their philosophy for fund raising in this way:

I would say that development is like this big fishing boat. You go park it where you think there are maximum schools of fish and you let the lines out. You have to be careful not to have too many lines and not to have crossed lines, but the more you ask, even with risking inefficiencies, the more money you are going to bring in.

This respondent clearly had the transactional perspective as donors were referred to as "fish" and organizational interactions as "lines" that may often become crossed. This analogy represents the challenges that could be experienced when isolated fund-raising integration strategies are used. In a similar vein, a respondent from Northgrowth State University expressed some discomfort in approaching a donor in a transactional way:

Periodically he would send us $\$ 1,000$ but nobody knew him. [A volunteer had said I should] just call him and ask him. Ask him for $\$ 50,000$. I put it off, and I put it off, because I couldn't see how it was going to go because he has no relationship. So I called him and said, "I'd like to come visit you; you've given in the past, I'd like to talk to you about a project we're working on." [He responded] "OK, but why are you coming?" So you try to talk around it, but eventually I finally had to say "I'm coming to ask you for money!" 
An isolated integration strategy is neither organizationally focused nor relationship driven. Isolated integration exchanges are occasional, transactional encounters that are driven by need and a perceived value from a transactional market perspective whereby each actor feels that he or she is getting something out of the interaction. ${ }^{33}$ There are definitely opportunities to use this type of strategy within an institution for the sake of efficiency (eg, a bookstore patron or football season ticket holder). However, if a long-term philanthropic relationship is the desired outcome, this short-term type of integration strategy is not the most effective strategy.

\section{Functional integration strategy}

The second type of organizational integration strategy is functional integration. This strategy denotes a high formality of interaction with the organization, but not a significant emotional or relational commitment. Respondents from Central State described their interaction with board members, who have a high degree of structural formality, as using this type of integration strategy:

[My board members] are used to coming and eating and nodding, and giving advice and walking away and coming to concerts and having a good time. But when you say, "Well, would you help us raise money?" [the board members say], "That's not my job! That's not why I'm here." And some prominent board members, who've been involved with the college a long time, they're not at all interested in raising money. They feel very uneasy about a requirement that they give money.

I go literally from event to event to event no real time is spent on the donor relationships other than in a very limited way.

A functional integration strategy is more organizationally focused, and the relational aspect (and often the donor) is considered secondary. This type of integration strategy may be useful as an introduction or entry point for an individual to get involved, but volunteers and donors who are left to languish may gradually feel disconnected from the organization, or may never progress toward more significant contributions because communication and motivation are driven almost exclusively by the organization, thus discounting the potential donor's feelings and interests. Again, as a long-term strategy functional integration could be challenging because prospective donors may become disenchanted when asked to give financially to a cause in which their perspectives and values are discounted or perhaps completely ignored.

\section{Latent/potential integration strategy}

The third type of organizational integration strategy is latent/potential integration. This strategy emphasizes the relationship between a donor (or potential donor) and an individual associated with the organization, while the formal connection to the organization is secondary. For the cases examined, this integration strategy was predominant, being evidenced by all nine respondents in over 100 passages. The reliance on latent/potential integration is consistent with fund-raising literature, which is adamant on the point that fund raising is relationally driven. ${ }^{34}$ However, relying exclusively on one relationship can be dangerous, especially if that one tie to the organization were to be extinguished, or if the donor were to feel that the 
relationship is contrived. One respondent from Flagship noted, "[Top donors] are highly suspicious of relationships and friendships, and one of the great, great concerns is that they [the top donors] are going to be taken for granted. And they are." Another respondent from Northgrowth noted how critical relationships were for their fund-raising strategy because of their institution's role in the community: "We are a public university, and that has a certain meaning for us. It means that we are accessible." Unfortunately, access to an individual within an institution and a strong relationship do not necessarily translate into enduring donor relationships. As a Central State respondent stated:

On the other hand, I can think of a few people that have really been on board [with vision of the institution], good friends, and they haven't given a lot. So what's happened? Why haven't they, and why have these [other] people? I don't know the answer to that; I'm not exactly sure whether we haven't hit the chord yet. You know, the university has a relationship with that person.

This respondent is representative of all three cases in recognizing relationships as critical, yet could not define why they did not have enduring donor relationships. The full integration strategy may hold the answer.

\section{Full integration strategy}

The fourth type of organizational integration strategy is full integration. Respondents in every case discussed factors that are evidenced in the full integration quadrant, which emphasizes a high degree of relational embeddedness and a high formality of structural interaction, yet all were spoken of as a goal or vision for the future. When respondents were asked to describe their ideal donor, who could be a specific individual or a composite, all discussed these donors in terms of the combined factors of relational embeddedness and formal structural interaction as defined by full integration. But the examples given by respondents were projections for the future and rarely donor-specific, suggesting that actual enduring donor relationships were difficult to quantify or may not yet exist. However, their thoughts validated the full integration strategy. A respondent from Central State perfectly illustrated the combination between structural and relational factors with this comment:

They have done more than just given to the college, but are actually involved in some way on a board, on a committee, or something like that. I think to some extent there is a personal connection with one of our staff or development officers; there is a personal relationship of sorts. More than donor, they really are a friend, not just of an individual, but they really feel a kinship with the college for one reason or another. They really feel like it is their college.

Clearly the respondents can visualize and conceptually identify the existence of full integration as a viable strategy, yet they do not regularly experience full integration with specific donors. Perhaps it is because they have not sought to implement specific strategies to manage those relationships purposefully.

\section{Practical Application}

The data from informants across all three cases support the constructs of the Donor/Organization Integration Model, ${ }^{35}$ and suggest that the key to truly enduring donor relationships is finding a fully 
integrative focus and strategy for fund raising at the institution-integrating donors with the institution in terms of both relational embeddedness and formal structural interactions. This research affirms that understanding the coordination, linkage, and interaction between the internal organizational structure and the relationships associated with that structure may improve fundraising effectiveness and efficiency, particularly with the current external environment of the public higher education organization. Fund-raising success is contingent on personal relationships, and continued resource acquisition from capable constituents requires awareness, evaluation, and strategic process planning. Based on the feedback from the informants in these three cases of public higher education institutions, the researchers conclude that organizations that embrace a proactive approach, awareness of the link between their formal structural interactions and the relational embeddedness interactions of their donor relationships, may improve their capacity for developing more enduring donor relations. This research is valuable because it provides education leaders with concepts and perspectives that could enhance their strategies in creating policy, dealing with the changing external environment, and coping with the rising necessity of finding additional resources for organizational survival and growth.

The Donor/Organization Integration Model provides a practical framework for higher education organizations to examine their interactions with donors. In which quadrant are fund-raising activities focused? How can strategies, policies, and institutional fund-raising activities be directed toward providing donors with strong relational and structural experiences? Are there isolated, functional, and latent/potential patrons who could be more fully integrated? How can frequency of interaction and the investment of time, talent, and treasure by the donor be utilized to provide the donor and the institution with a more worthwhile relationship and experience? Seeking the answers to these questions can help institutional administrators create strategies that go well beyond give and take to provide an alternative to declining legislative and endowment support.

Future research should include application of this model to a broader sample of higher education organizations, as well as empirical testing to examine common patterns and processes associated with fund-raising practice. While this model considers the parameters of fund raising in three institutions of higher education, individual institutional success may be constrained by a number of factors such as organizational size, history, number of alumni (thus potential pool of obviously linked donor prospects), available fund-raising staff, the experience of the staff, size of the institutional endowment, reputation of the organization, and a myriad of other attributes that make college campuses virtually inimitable. Essentially, each institution will have unique characteristics that will enhance or inhibit their fundraising potential, and each organization must operate within the limitations of their environment. However, while they are unique, each organization will have a relational embeddedness and formality of structural interaction aspect to their institution that can be assessed and integrated to some degree for improved fund-raising performance. While the scope of the proposed model is intended for higher education organizations, the model may also apply to fund raising within other contexts. However, the model 
should be examined for such generalizability by future research.

\section{Conclusion}

This article has presented evidence that reflects the Donor/Organization Integration Model and fits its constructs to a specific set of public higher educational institution cases. While these cases are unique and may not be representative of fund raising in all public higher education institutions, they do demonstrate that the three constructs of relational embeddedness of interaction, formality of structural interaction, and integration were clearly present in their fund-raising strategies and experiences. Primary and secondary factors further support the alignment with and description of each of the three model constructs. In addition, the four types of organizational integration strategies for fund raising suggested by the model were supported and further described. The insights shared by the respondents as well as the factors identified may be a critical key to developing better fund-raising strategies that take advantage of integration between donors and the organization that will benefit public higher education institutions as they create enduring donor relationships.

\section{Appendix A: Individual Case Context}

For this study, each of the three institutions of higher education represented a case with the unit of analysis at the organizational level. Pseudonyms were chosen to represent the characteristics of each higher education institution.

\section{Central State College (Carnegie Classification: Baccalaureate/Associate)}

Central State College is an emergent institution established in the 1940s that addresses the needs of a thriving suburban community. Central is an exclusively commuter campus with a full-time enrollment of approximately 14,500 that focuses on open educational access and specific high interest associate and baccalaureate programs. The fund-raising operation has existed in a formal way for less than 20 years, and operates within a primarily centralized structure. Donor loyalty is high, but the number of donors is very modest. A significant challenge faced by this institution is identifying and engaging a donor base that includes more alumni. Currently most donors are community related and are primarily "friends" of the college who did not attend school at Central State.

\section{Northgrowth State University (Carnegie Classification: Masters II)}

Northgrowth State University began as an academy in the 1800s and evolved to university status in the mid 1990s. It is primarily a commuter campus with a limited number of residential students. With full-time enrollment of approximately 17,000, Northgrowth serves a wide-range of technical, professional, and liberal arts educational programs up to the master's degree level. The fund-raising operation has existed for approximately 30 years, but has been formalized in the last 15 years. They have successfully completed a moderate capital campaign, and have a mostly centralized structural strategy. However, major gifts officers have decentralized service accountability. A key to their fund-raising effort is the personal flavor of nearly all community partnerships that they have built with the local geographic area where the majority of their students and alumni reside. While Northgrowth has a modest pool of significant donors and friends, they have a significant 
fund-raising challenge in connecting more meaningfully with their alumni for a larger donor base because past fund raising has relied on a rather limited number of key donors.

\section{Flagship University (Carnegie Classification: Research I/Doctoral)}

Flagship University also began in the 1800s and has been the primary public institution of the state since inception. It is a commuter campus, with a 15 percent residential population, and a full-time student population approaching 18,000. Flagship's alumni base is over 200,000 and they enjoy a fierce loyalty and emotional commitment from alumni throughout the state and in the western United States. Their mission and focus is research. They have completed many capital campaigns and are currently preparing for a new campaign targeted at a goal of nearly $\$ 1 \mathrm{bn}$. Their fund-raising function formally began in the 1960s. Their current fund-raising structure is almost exclusively decentralized, with an estimated development staff between 300 and 350 for the university. Of the three institutions, Flagship has felt the decline in state funding most sharply and cite their most challenging fund-raising issue to be developing consistent numbers of mid-to-high-level major gift donors $(\$ 100,000-\$ 999,999)$.

\section{Appendix B: Definitions and Examples of Relational Embeddedness Interaction}

\section{Interpersonal activity}

When two or more actors interact with one another. Activity that occurs between two people that is not economically driven; eg, "We are pretty informal, if I need something, I can pick up the phone and call" (Northgrowth); "It is usually a discussion. I'd say that is one of our strengths ... the rapport, the relationship with our best donors" (Flagship).

Control in relationship The need, assignment, or responsibility to determine how things happen within a relationship.

Reciprocation of caring Taking care of someone who takes care of you. Not in a quid pro quo way, but wanting to sincerely go out of their way to express gratitude.

Honest broker, treats fairly Someone who has the interests of the donor as the primary focus before the needs of the institution

Credit and recognition The recognition for results accomplished. Motivation for relationship.

\section{Social and economic relationships}

Also called relational embeddedness, defined as the combination of social and economic activity between two individuals;" eg, "I got him on the National Advisory Council and be said to our Vice President, how is the engineering building coming? The VP said we just need that base gift, we need someone to step up and make the major gift. He said, 'talk to me about that' and that led to the $\$ 6 m$ gift" (Flagship).

Relational contracting Governing relationships by virtue of personal interaction, trust, and sanctions for future relationships, reputation, and third-party trust. 
Personal networking

Building a web of relationships for personal benefit. It's whom you know, not what you know.

\section{Donor relations}

Activities and efforts by the organization to develop relationships with donors. The formal and informal programs and activities that build the ties of donors with the organization; eg, "I think with any of the donors one thing we have been able to connect with them in terms of involving them in something. We've been able to identify the thing they are really committed to do, and they like it. They are involved in committees. They have done more then just given to the college, but are actually involved in some way on a board, on a committee, or something like that" (Central State).

Donor trust

Frequency of contact

Expressing appreciation
An understanding from the donor's perspective that they can believe what someone tells them based on their past experience, that their interests will be considered and protected, and that they won't be taken advantage of. How often internal contacts interact with donors. The frequency with which institutional representatives initiate formal or informal contact with the donor, eg, daily, weekly, monthly.

Expressing gratitude, thanks for efforts exerted, particularly in the case of donors.

\section{Donor feedback}

How donors feel about the institution's fund-raising operation. What type of input or response have they given; eg, "We get comments from people in the community to our staff or to other people on campus, it could come from a number of different sources. Some people might even talk to the president, and say 'oh, by the way, the alumni ought to do this or that ..." "' (Flagship).

Two-way communication

Frequency of feedback
Sharing a message. Creating understanding by having information flow in both directions.

How often donors and internal contacts interact. With donors it would be the frequency with which they initiate formal or informal contact with the organization. eg, daily, weekly, monthly. 


\section{Appendix C: Definitions and Examples of Formal Structural Interaction}

\section{Internal organization:}

Within the organization's recognized boundaries; eg, "We are in some respects still trying to solidify the internal organization, as opposed to being perhaps as sensitive or organized about the external group" (Central State).

The formal and informal differentiation and integration of
tasks and responsibilities.
Operations, processes, and activities within the organization
that are sanctioned and mandated by the people and
policies within the organization.
"How we do things around here..., , what people expect
and understand of how things work within the
organization. The prevailing values, traditions, and social
norms of the organization.
A development operation or activity that is disconnected
structurally for individual units that make up the whole
organization. The individual units may or may not have
redundant structures for their areas.

\section{Roles for external actors}

The position or role that someone outside of the organization may take to support the organization, eg, 'We can't focus on only one area. Some people, believe it or not, actually like to be legislative advocates. Others just hate it. Some people will go and fund raise for you and others hate it. So you can include community service, and others feel like they do enough for their church or service group, and they don't want to do any more. So you really have to figure out how to engage the broad spectrum of people in something (Flagship).

Volunteers People who give of their time and energy to support the institution and its mission. People who are not "officially" assigned a formal position, or have formal responsibilities and accountability as an employee within the institution.

Alumni People who are connected to an institution or organization by virtue of their past affinity role. Usually used to denote former students of an institution.

Donor

Anyone who gives something of value to an organization with no expectation of anything in return. Usually a role identified in reference to monetary gifts given to the institution.

\section{Challenges for fund raising}

Factors that keep an organization from achieving its fund-raising goals, eg, "I think ... the biggest challenge is developing a vision of what fund raising is all about. Teaching people to understand what this is all about. So we're all learning. Part of it is we are all struggling to kind of pull it together (Central State). 
Strategic vision

Competition

Dual reporting conflicts
The overall ideal or future picture of what fund-raising efforts can and should look like within the institution's fund-raising operations.

The dynamic conflict or tension when two entities seek to outdo one another. Competing for something scarce, or to be "better" than the other. This can be within the organization, between individuals, or between organizations. The tension of reporting to two leaders. An individual or campus unit may be related to the fund-raising side of activity, and they also may be institutionally related.

\section{Fund-raising process}

The means and process (internal and external to the organization) of generating and receiving financial donations (gifts) from donors in support of the organization, eg, "All the hand works better together then one finger (Central State).

Annual fund

Data management

Making the ask
The yearly, or annual, fund-raising appeals process usually used for a large number of donors.

How information is processed, stored, and shared within the organization. How are notes, contacts, and donor information managed?

The act of the organization asking the donor for their support: requesting a gift.

\section{Evaluation and assessment}

How does the organization compare its current and past fund-raising performance to itself and others? eg, 'We're looking at that all the time, in fact we had a consultant in this summer, and we're reviewing our organization. We'll probably make some very substantial changes in the way we're structured and the frequency of board meetings, what we ask of volunteers and things like that. We really evaluate that pretty well on an annual basis (Northgrowth).

Peer institutions

Benchmarking/statistical evaluation
An institution that has like demographics and characteristics that is used for comparison or benchmarking to gauge success, progress, and need for improvement. Looking at data collected related to institutional performance and making decisions based on statistics analysis. 


\section{Appendix D: Definitions and Examples of Integration}

\section{Coordination}

Coordinating or working together to integrate fund-raising activity and operation.

Cooperating. Correlation, eg, "You can't do anything you want, but you can talk to anyone you want is my philosophy" (Northgrowth); "Anyone can talk to anybody, it is when you ask for money that we have to have the clearance." (Flagship).

Integration

Working to put the "pieces" of the organization together in a way that makes sense. Synergy and involvement of donors and others on the "inside" of the organization

Synergy Examples of meeting the needs of both the donor and the organization. "equilibrium" in the supply vs. demand tension.

\section{Structural embeddedness}

How well the people in a certain person's network know the other people in the network. If $\mathrm{A}$ is friends with $\mathrm{B}$ and $\mathrm{C}$, do $\mathrm{B}$ and $\mathrm{C}$ also know one another? The architecture of the connection of people and relationships within a network, eg, "Now we have other members on the board who are doing business with each other. Why? Because they are doing business with the institution" (Central State).

Brokered relationships

The idea that one individual is arranging or "brokering" a relationship with another individual for a third party

Power and influence The perceived or actual ability to change the circumstance, outcome, or activity within a specific environment.

\section{Positioning and visioning}

The overall plan for deploying resources for a favorable market position. The use of specific tactics to accomplish the overall strategic focus for fund-raising efforts. The plan to build a competitive advantage, eg, "There are two or three things that will be important. One is to continue to steward well. Second is to build connections with people. Obviously, alumni's giving is very important to us. So what we're going to have to do as an institution, between this campaign and the next campaign, is really be out there building connections" (Northgrowth).

Donor inclination

Planning and priorities

Resources

Types of gifts
The opportunity for the donor to determine gifting interest, direction, and timing. The donor is the primary driver in the process of fund raising and strategies selected by the organization. This assumes a dialogue that is two-way symmetrical between donor and organization and organization and donor. How does the institution differentiate between competing needs? What is the first area of focus? Human, physical, financial: the raw materials in the organization that help get things done. The type of gifts that are given to an institution: cash, real estate, planned gifts, gifts-in-kind, and bequests. 


\section{Boundary spanning}

When internal organizational members interact with external constituents they "bridge" the inside with the outside. Scanning, monitoring, communicating, eg, "I think that we belp interact between, I think that if you're talking the President/Vice President working with donors, we act as the intermediary between them. If you are talking between deans and donors, I think that yes, we do mediate or help bring those two factions together" (Northgrowth).

\section{Communication}

Environment

Community

\section{Sharing a message. Creating understanding. Boundary} spanning roles require messages to be delivered. Internal or external, it is the context where fund raising and organizational activity happens. Boundary spanners must assess what is happening in the environment relative to the institution.

"Town and gown" idea of the community dealing with the organization and gaining benefits or being a stakeholder in what happens at the institution.

\section{References}

1. P. G. Altbach (2004), "The costs and benefits of world-class universities," Academe, 90, 1, pp. 20-3; H. G. Bloland (2002), "No longer emerging, fund raising is a profession," CASE International Journal of Educational Advancement, 3, 1, pp. 7-19; J.-G. Mora and M. Nugent (1998), "Seeking new resources for European universities: The example of fund-raising in the US," European Journal of Education, 33, 1, pp. 113-40.

2. S. M. Cutlip ([1965] 1990), Fund Raising in the United States: Its Role in America's Philanthropy, Transaction Publishers, New Brunswick, NJ; R. Gonzales-Campoy (1996), "Answering the call for help," NSFRE Advancing Pbilantbropy, Spring, pp. 36-40; P. D. Hall (1992), Inventing the Nonprofit Sector and Other Essays on Philanthropy, Voluntarism, and Nonprofit Organizations, Johns Hopkins University Press, Baltimore, MD; J. J. Havens and P. G. Schervish (2001), "Wealth and commonwealth: New findings on wherewithal and philanthropy," Nonprofit and Voluntary Sector Quarterly, 30, 1, pp. 525; R. A. Prince and K. M. File (1994), The Seven Faces of Philanthropy, Jossey-Bass, San Francisco.

3. T. L. Chung-Hoon, J. Hite, and S. Hite (2004), "Factors for financial success: organizational infrastructure practices for effective donor relationships in public higher education," paper presentation at American Education Research Association (AERA), San Diego, CA, April 16, 2004

4. Altbach (2004), op. cit.; J. Barney (1991), "Firm resources and sustained competitive advantage," Journal of Management, 17, 1, pp. 99-120; I. Dierickx and K. Cool (1989), "Asset stock accumulation and sustainability of competitive advantage,"

Management Science, 35, 12, pp. 1504-11; J. M. Whipple and R. Frankel (2000), "Strategic alliance success factors," Journal of Supply Chain Management, 36, Summer, pp. 21-8.
5. Chung-Hoon et al. (2004), op. cit.

6. Altbach (2004), 'op. cit.

7. Barney (1991), op. cit.; J. H. Dyer, P. Kale, and H. Singh (2001), "How to make strategic alliances work," MIT Sloan Management Reviere, 42, 4, pp. 3743; B. Uzzi (1997), "Social structure and competition in interfirm networks: The paradox of embeddedness," Administrative Science Quarterly, 42, pp. 35-67; B. Uzzi (1999), "Embeddedness in the making of financial capital: How social relations and networks benefit firms seeking financing," American Sociological Review, 64, August, pp. 481-505.

8. Chung-Hoon et al. (2004), op. cit.

9. Council for Aid to Education (2003), "Gifts to higher education drop for the first time in 15 years; giving by alumni shows biggest drop," press release, March 13; K. L. Jackson and J. C. Glass, Jr. (2000), "Emerging trends and critical issues affecting private fund-raising among community colleges," Community College Journal of Research and Practice, 24, 9, pp. 739-54.

10. American Association of Fund Raising Counsel (AAFRC) (2003), Charity Holds Its Own in Tough Times (Giving USA 2003, The Annual Report on Philanthropy for the Year 2002). Indianapolis, IN: AAFRC Trust for Philanthropy.

11. Ibid; American Association of Fund Raising Counsel (AAFRC) (2002), Giving USA 2002: AAFRC Trust for Philantbropy, vol. 47. Indianapolis, Indiana: AAFRC Trust for Philanthropy.

12. P. G. Schervish and J. J. Havens (1997), "Social participation and charitable giving: A multivariate analysis," Voluntas: International Journal of Voluntary and Nonprofit Organizations, 8, 3, pp. 235-60.

13. A. S. C. Grant (2001), Major Gift Donor Stereardship in Higher Education, Ph.D. Dissertation No. DAI-A 62/08, p. 2695, Feb 2002, Washington State 
University, Pullman, WA; Havens and Schervish (2001), op. cit.

14. Chung-Hoon et al. (2004), op. cit.

15. Ibid.

16. Ibid.

17. M. S. Granovetter (1973), "The strength of weak ties," American Journal of Sociology, 78, 6, pp. 136080; J. M. Hite (2003), "Patterns of multidimensionality among embedded network ties: A typology of relational embeddedness in emerging entrepreneurial firms," Strategic Organization, 1, 1, pp. 9-49; J. M. Hite and W. S. Hesterly (2001), "The evolution of firm networks: From emergence to early growth of the firm," Strategic Management Journal, 22, pp. 275-86; B. Uzzi (1996), “The sources and consequences of embeddedness for the economic performance of organizations: The network effect," American Sociological Review, 61, August, pp. 674-98; J. M. Hite (2005), "The evolution of relationally-embedded network ties," Entrepreneurship Theory and Practice, 29, 1, pp. 113-44.

18. B. Manor (1987), "Organizational boundary spanning in institutionalized environments," Academy of Management Journal, 30, 3, pp. 456-77; R. H. Miles (1980), "Organizing boundary roles and units," in Macro Organizational Behavior, Scott, Foresman, Glenview, IL, pp. 110-19.

19. Chung-Hoon et al. (2004), op. cit.

20. Carnegie Foundation (2000), Carnegie Classification: The Carnegie Classification of Institutions of Higher Education, available online at http:// www.carnegiefoundation.org/Classification/ index.htm.

21. M. J. Worth and J. W. Asp (1994), The Development Officer in Higher Education: Toward an understanding of the Role (vol. Report No. 4), The George Washington University, Graduate School of Education and Human Development, Washington, DC.

22. QSR (2001), QSR Nvivo, Version 1.2. QSR International Pty Ltd, Victoria, Australia.

23. D. A. Erlandson, E. L. Harris, B. L. Skipper, and S. D. Allen (1993), Doing Naturalistic Inquiry: A Guide to Methods, Sage Publications, Newbury Park, CA; A. Strauss and J. Corbin (1998), "Grounded theory methodology: An overview," in N. K. Denzin and Y. S. Lincoln (Eds.), Strategies of Qualitative Inquiry, Sage Publications, Newbury Park, CA, pp. 158-79.

24. Chung-Hoon et al. (2004), op. cit.

25. J. M. Hite (2003).," "Patterns of multidimensionality among embedded network ties: A typology of relational embeddedness in emerging entrepreneurial firms," Strategic Organization, 1, 1, pp. 9-49.

26. K. S. Kelly (1998), Effective Fund-Raising Management, Lawrence Erlbaum Associates, Mahwah, NJ.

27. M. S. Granovetter (1985), "Economic action and social structure: The problem of embeddedness," American Journal of Sociology, 91, 3, pp. 481-510; M.
S. Granovetter (1990), "The old and the new economic sociology: A history and an agenda," in R. Friedland and A. F. Robertson (Eds.), Beyond the Marketplace, Aldine de Gruyter, New York, pp. 89-

112; J. Hite and S. Hite (2003), "Understanding the old boy's network: A network perspective of educational leadership," UCEA Presentation Paper Draft, Portland, OR, p. 33; Uzzi (1996), "The sources and consequences of embeddedness for the economic performance of organizations," op. cit.

28. Kelly (1998), op. cit.

29. Chung-Hoon et al. (2004), op. cit.

30. H. E. Aldrich and D. Herker (1977), "Boundary spanning roles and organization structure," Academy of Management Revierw, 2, April, p. 219; E. B. Goldring (1995), "Striking a balance: Boundary spanning and environmental management in schools," in S. B. Bacharach and B. Mundell (Eds.), Images of Schools: Structures and Roles in Organizational Behavior, Corwin Press, Newbury Park, CA, pp. 283314; J. E. Grunig and T. Hunt (1984), Managing Public Relations, New York, Holt, Rinehart, and Winston; Kelly (1998), Effective Fund-Raising Management, op. cit.

31. Havens and Schervish (2001), op. cit.; P. G. Schervish (2001), "The spiritual horizons of philanthropy: New directions for money and motives," in E. R. Tempel and D. F. Burlingame (Eds.), Understanding the Needs of Donors: The Supply Side of Charitable Giving, Jossey-Bass, San Francisco, no. 29 , pp. 17-32.

32. Chung-Hoon et al. (2004), op. cit.

33. O. Williamson (1979), "Transaction cost economics: The governance of contractual relations," Journal of Law and Economics, 22, 2, pp. 233-61.

34. K. A. Chandler (1999), Formal and Informal Relationships in the Arts: A Case Study of an Advisory Council and its Network in Higher Education, unpublished Ph.D. dissertation, New York University; M. B. Drummond (1997), The Power of Money: Colleges and Universities Bank on the BoundarySpanning Roles of Development Officers, unpublished Ed.D. dissertation, Oklahoma State University; M. R. Hall (2002), "Building on relationships: A fundraising approach for community," Community College Journal of Research and Practice, 26, 1, pp. 4760; Schervish and Havens (1997), op. cit.

35. Chung-Hoon et al. (2004), op. cit.

36. Granovetter (1985), 'op. cit.; Granovetter (1990), op. cit.; A. L. Larson and J. A. Starr (1993), "A network model of organization formation," Entrepreneurship: Theory and Practice, 17, 2, pp. 5-15; B. McKelvey and H. Aldrich (1983), "Populations, natural selection and applied organizational science," Administrative Science Quarterly, 28, 2, pp. 101-28; Uzzi (1996), op. cit.

37. P. R. Lawrence and J. W. Lorsch (1967), "Differentiation and integration in complex organizations," Administrative Science Quarterly, 12, 1, pp. 1-47. 